\title{
Tools to Support the Development and Promotion of Innovative Projects
}

\author{
Dilshod Okhunov ${ }^{1 *}$, Sergei Semenov ${ }^{2}$, Saidahror Gulyamov ${ }^{3}$, Dilorom Okhunova ${ }^{4}$, and Mamatjon Okhunov ${ }^{5}$ \\ ${ }^{1}$ Fergana branch of the Tashkent University of Information Technologies named after Muhammad Al-Khorazmiy, 150100, Fergana \\ city, Republic of Uzbekistan \\ ${ }^{2}$ Research Institute "CENTERPROGRAMSYSTEM”, CJSC 170024, Tver city, Russian Federation \\ ${ }^{3}$ Tashkent State University of Economics, 100066, Tashkent city, Republic of Uzbekistan \\ ${ }^{4}$ Regional Department of Finance, 150103, Fergana city, Republic of Uzbekistan \\ ${ }^{5}$ Ferghana Polytechnic Institute, 150101, Fergana city, Republic of Uzbekistan
}

\begin{abstract}
Competitiveness and efficiency in the modern economy are based on innovation. It is necessary to ensure the flow of well-founded innovative projects. This requires funds to support the creation and promotion of these projects. These tools include innovation methodology, mathematical models and methods, software and information tools, and other types of software. All these tools are implemented as services of a digital platform based on cloud technologies and available to various categories of users. This platform is being developed in research Institute of CPI, Tver, Russia.
\end{abstract}

\section{Introduction}

The innovation economy differs from the previous models of economies primarily by the need for constant changes in all elements of production and economic relations. In the economies of mass and mass production, the concept of efficiency was associated with the concept of stability for a certain period of time. In the innovation model, efficiency is primarily associated with the concept of competitiveness. The global nature of competition, the common information space, and the diversity of goods and services require any manufacturer and supplier to be flexible in making decisions and adapting to competitive conditions. Constant search and implementation of changes at different levels of production and economic relations are necessary conditions for competitiveness, regardless of the type and scale of activity.

It is the change in economic ideology that leads to the need to introduce a new concept of "innovation" as a unit for assessing the degree of changes in production and economic relations.

The key role in the formation of the philosophy of innovative economy belongs to information technologies (IT). This is due to the following important factors.

First, there is a short information link between all the elements of the production and economic system. The speed of decision-making and information exchange is a determining factor in the efficiency and competitiveness of any system.

Secondly, the safety of information. The information necessary for decision-making today has a very wide variety of forms and representations. The volume of this information is very large and is constantly growing. The ability to save the accumulated information is the most important factor in the success of any activity.

Third, the availability of information. Regardless of the scale of the task to be solved, it is necessary to be able to obtain information not only from local sources (the enterprise information system, the local database), but also from the global information space. This is due to the variety of factors that influence decision-making in the context of working in the global economic system.

Fourth, a high degree of automation of information processing. Information is often created when solving some problems, and can be used to solve others. Therefore, the ability to quickly transform information to the right form for decision-making is also a crucial factor in the need for IT.

Fifth, the ability to transform information into a form of knowledge. Knowledge differs from information in its pragmatic aspect: what to do with this information or what to do if this information is obtained. For the speed and quality of decisions, knowledge is a more valuable source of competitiveness and efficiency, as well as an object of legal protection. Modern IT allows you to effectively transform information to the form of knowledge and work successfully with them.

Ultimately, the innovation economy depends largely on the success of the use of IT capabilities, which are one of the three cornerstones of the innovation economy. IT as a type of production activity has its own characteristics, and this article is devoted to this. 
To understand the philosophy and ideology of the innovation economy, it is necessary to focus on its basic elements: concepts and definitions.

The term "innovation" is now one of the most widely used in the economic literature and in public speeches. Dozens (and perhaps even hundreds) of its definitions and interpretations are known. And this is quite natural for the era of the global innovation economy. However, there is still no clear understanding of this term and, most importantly, the essence of the concept itself.

While the Russian economy went its own way, not caring about competitiveness and efficiency, terminological disputes were the lot of scientists. But by joining the WTO, Russia is forced to play by the general economic rules, otherwise the domestic industry will simply disappear under the onslaught of more efficient foreign companies and technologies.

Why is it so important to understand the terms and concepts?

The fact is that there is a structural restructuring of the economic model. The role of the state in this process is crucial: it creates a new infrastructure and launches cash flows into a new economic model. Here, the negative consequences of conceptual illiteracy are fully manifested. The money is being used, and nothing positive is happening. Competitiveness, efficiency and productivity remain at the same level or even decline.

Due to the total lack of understanding of the new concept, there is a "gluing of a new label on the old concepts"everywhere. Now everywhere you can see how the doors of offices, products and technologies are labeled "innovative" and expect a miracle: how the economy will suddenly become efficient and competitive.

Let's try to sort out the confusion in terminology and concepts.

First, it is necessary to immediately determine that innovation is not the result of the evolutionary development of the previous economic model, but a revolutionary transition to a new model. And there can be no continuity in the concepts. However, it should be noted that the "product based on invention" model is not new in itself, moreover, it is already many thousands of years old. And the model of "goods based on the study of demand" is quite young (in historical terms), and it arose with the advent of mass production industry. But it was the last 150 years of industrial revolutions that made us forget about inventions as the main source of new goods. Of course, to facilitate understanding, sometimes it is necessary to use some analogies with elements of the old model, but it is analogies, and not direct inheritance of a term or concept.

The reason for the total misunderstanding of the innovation economy lies in the attempt to find direct analogies in the old model and make the old economic mechanism work in a new way. Hence the desire to use the old terminological and conceptual apparatus.
Of course, it is not only and not so much in terms, but in a lack of understanding of the essence of the new concept and new processes. This leads to both wrong decisions and wrong actions.

Secondly, the concept of "innovation" refers to the so-called indefinable concepts [1]. An indefinable concept in axiomatics is an initial, basic concept, which cannot be unambiguously defined. Any science and theory is based on some basic concepts, usually intuitive and having properties described by the axioms of this theory. So, the main undefined concepts in geometry are point, line, plane, volume, space, in mathematicsnumber, set, correspondence, in physics-time.

That is, an indefinable concept cannot be uniquely defined through other basic concepts of a given theory.

It follows that there can be innumerable" correct " definitions of this concept. And all of them, in a certain sense, will be both right and wrong at the same time. That is, a concept formulated quite strictly and precisely for one specific task may be completely unacceptable for another.

There is some contradiction between the generality and the usefulness of the definitions. The most general definition of a concept is usually the most useless. On the other hand, a very specific definition makes it useful only in a very narrow range of tasks. And this is constantly traced in everyday life. So, there are several hundred definitions of the concept of "system" and several dozen of the concept of "marketing". Definitions are most successful only in specific situations.

Third, the concept of "innovation" is multifaceted and multidimensional. This is a philosophy, an object, a function, an action, properties, and a method. An attempt to map a multidimensional object to a plane (or line) only gives the correct representation within that plane or line. This reasoning would be a mathematical abstraction if the tens of thousands of people and businesses trying to operate in an innovative economy did not suffer from "correct" definitions that kill innovation and innovation activity in the bud.

Fourth, there is a need for a common denominator in decision-making for all stakeholders. The fact is that each of them is incompetent in innovation in its own way: the investor understands money, the inventor understands machines, and the general definition does not help either of them. The working definition of innovation should help all parties, it should reflect the essence of the invention, the idea. The market situation is in innovation. Money matters - in innovation. Innovation is the top of the concept tree, the individual branches of which are the view of each interested party on innovation (through an idea, through money, through a market position, through production opportunities, etc.).

\section{Analysis of existing definitions of the concept "innovation"}


Let's see how the concept of "innovation" is defined in a number of primary sources and some modern documents. An analysis of the existing definitions reveals a wide variety of views and approaches.

Schumpeter, J. A. In [2], under innovation, he proposed to understand any possible change that occurs due to the use of new or improved solutions of a technical, technological, organizational nature in the processes of production, supply, sales of products, etc.

Foster R. defines innovation as a battle in the market between innovators (or attackers) - those who try to make money by changing the order of things - and those who defend themselves by protecting their current income [3].

Twiss B. interprets innovation as an offer on the market of something new, for which the consumer is willing to pay [4]. An invention becomes an innovation if it is successful in the market. Innovation is an application, that is, a process in which an invention or idea acquires an economic content.

According to Santo B., innovation is a social, technical or economic process that, through the practical use of ideas and inventions, allows you to create the best products and technologies that can bring additional income on the market [5]. Innovation is a technical and economic cycle in which the use of the results of research and development directly causes technical and economic changes that affect the activities of a particular field.

Drucker P. defines innovation as a special tool of entrepreneurs, a means by which a chance to open a new type of business or service is realized [6].

For Porter M., innovation is an opportunity to gain competitive advantages [7]. Innovations in a broad sense include both new technologies and new working methods. Innovation manifests itself in a new product design, in a new production process, in a new approach to marketing, or in a new methodology for improving the skills of employees. Innovations are fairly simple and small, based more on the accumulation of minor improvements and achievements than on a single major technological breakthrough.

Hamel G. and Prahalad K. believe that innovation is what brings the maximum profit, ahead of others on a global scale [8].

According to Nelson R. and Winter S., innovation is a change in routine. Viability depends on how consumers evaluate it [9].

In the OECD Frascati Position, innovation is the end result of an activity, embodied in the form of a new or improved product introduced in the market, a new or improved technological process used in practice, or in a new approach to social services.

Yakovets $\mathrm{Yu}$. He believes that innovation is a qualitative change in production, which can relate to both technology and technology, as well as forms of production organization and management [10].
Morozov Yu. defines innovation in a broad sense as the profitable use of innovations in the form of new technologies, products and services, organizational, technical and socio-economic solutions of a production, financial, commercial, administrative or other nature [11].

According to Fatkhutdinov R., innovation is the final result of the introduction of new products in order to change the object of management and obtain an economic, social, environmental, scientific and technical or other type of effect [12].

According to the definition of V. Medinsky, innovation is an object introduced into production as a result of scientific research or discovery, qualitatively different from the previous analog [13].

Hipel V. defines innovation as the application of a new product or process in practice [14], and Rigs H.-as the commercial development of a new idea [15].

Freeman K., speaking about industrial innovation, defines it as technical, design, production, management and commercial activities, the production of new (improved) goods or the first commercial use of new (improved) processes or equipment [16].

Rothwell R. and Gardiner P. believe that innovation is not only the commercialization of a major improvement in a technical process (radical innovation), but also the use of small-scale changes in technological skills (improvements or minor innovations) [17].

Tidd D., Bessant D., Pavit K. define innovation as the process of turning opportunities into new ideas that are widely implemented in practice [18].

In the Law of Ukraine on Innovation Activity [19], innovations are newly created (applied) and (or) improved competitive technologies, products or services, as well as organizational and technical solutions of a production, administrative, commercial or other nature that significantly improve the structure and quality of production and (or) the social sphere. An innovative product is the result of research and (or) development work that meets the requirements established by this law. Innovative products - new competitive goods or services that meet the requirements established by this law.

Wikipedia gives the following definitions [20]. Innovation is an implemented innovation that provides a qualitative increase in the efficiency of processes or products that are in demand by the market. It is the end result of a person's intellectual activity, imagination, creative process, discoveries, inventions, and rationalization. An example of innovation is the introduction to the market of products (goods and services) with new consumer properties or a qualitative increase in the efficiency of production systems. Innovation - a new or significantly improved product (product, service) or process, a new sales method, or a new organizational method in business practice, workplace organization, or external relations. Innovation is not any innovation or innovation, but only one that seriously improves the efficiency of the current system. 
Generically, this concept can also be applied to a creative idea that has been implemented.

\section{Methodical section}

In an innovative economy, it is very important to increase the number of innovative projects being implemented. At the same time, it is necessary to create conditions for improving the quality of project development.

These conditions are implemented in four ways (see Figure. 1)

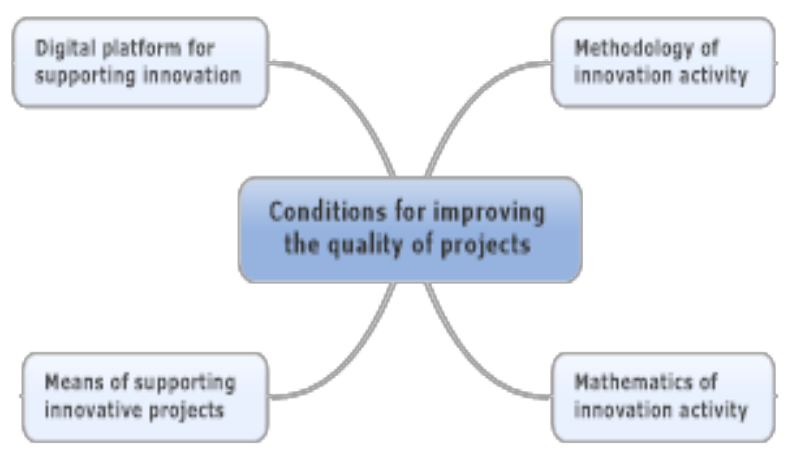

Fig. 1. Conditions for improving the quality of projects

These conditions are implemented on a digital platform for supporting innovation activities and innovative projects (next DP).

The digital platform for supporting the creation and promotion of innovative projects solves the following basic tasks:

- The methodology of innovation activity in various fields is developed and supported.

- Supports the creation and promotion of an innovative project.

- Information and methodological support for the user is provided.

- Communication between subjects interested in an innovative project is provided.

- The project is evaluated from different points of view.

- Work with intellectual property is supported.

The DP itself is an innovative project. At the initial stage of DP development, the main technical solutions were conceptualized and justified. The DP is represented as subsystems, blocks, and services. Solutions to fundamental problems in the creation and promotion of innovative projects, as well as problems of innovation management, have been worked out.

The initial step in this project is to develop an innovation Methodology. This allows, first of all, to form an optimal organization of innovation activities. Secondly, it is most effective to automate the solution of innovation tasks [21].

The methodology is developed based on the definition [22]. "Methodology is the teaching about the organization of activities."

The methodology of innovation activity elaborates the basic concepts of this activity:

Characteristics of innovative activity: Features, Principles [23], Conditions, Norms of this activity.

Logical structure of innovative activity: Subject, Object, Subject, Forms, Means, Methods, Result of activity.

Time structure of activity: Phases, Stages, and Steps of activity.

The methodology can generally be developed for any type of activity, taking into account terminology, application rules, automation conditions, etc.

Based on the basic concepts of the methodology (theoretical plan), the system and applied concepts of the applied field are worked out.

For example, an innovative project, an innovative activity, an innovative system, an innovative infrastructure, stakeholders, an innovative product (product, technology, service), efficiency, competitiveness, feasibility, investment system, stages, intellectual property, etc.

From basic concepts, on the one hand, the study is conducted in the direction of detail to elementary facts.On the other hand, we are building integrated concepts based on basic concepts and elementary facts (for example, a "well-packaged" project).

On the basis of terms of varying degrees of detail, an ontological network of concepts of innovation is constructed.

The main problems (goals) of innovation that require automated support should be recognized:

- Increasing the motivation of participants in innovation activities.

- Increasing the validity of innovative projects.

- Improving the ease of working with innovative projects.

- Reducing the subjective factor when evaluating and making decisions about supporting an innovative project.

Solving these problems will significantly increase the flow of "well-developed" innovative projects. Implementation of these projects will allow creating a wide range of competitive and effective products [24].

To solve the fundamental problems of innovation, it is necessary to solve many problems of different levels and complexity related to:

- Evaluation of the innovation project (its parts) according to several criteria;

- Justification of the novelty, feasibility and effectiveness of the innovation project;

- Preparing a decision to support (or reject) the project;

- Monitoring and managing project progress;

- Various calculations, project presentation, etc.

Various mathematical methods and models are used to solve these problems.

The DP project addresses the following issues:

- Measurement and evaluation of elements of an innovation project and elements of innovation activity.

- Decision-making on an innovative project and the possibility of its support at the stages of the life cycle.

- Analysis of data obtained from our own and third-party sources (information resources). The possibility of using information from data Centers (Big data) is considered.

- Modeling of objects and processes of innovation (including simulation of the consequences of applying the results of an innovation project).

- Management of innovation activities at different levels (from the workplace of a specialist to the level of the relevant Ministry).

- Investment mathematics that solves the problems of 
substantiating the effectiveness and competitiveness of innovative projects.

The third branch of Figure 1 "means of supporting innovative projects" includes various types of support. For example, information, methodological, financial, regulatory, organizational, and other types of support.

The fourth branch of Figure 1 deals with the creation of the digital platform for supporting innovative projects and innovative activities [25].

The DP is developed as a self-organizing and selfdeveloping system that integrates its own and third-party information resources.

Templates and scenarios for the formation of innovative projects within the use of the DP are being worked out.

The DP architecture is represented as interconnected subsystems, blocks, and services based on a cloud platform.

The DP consists of the following subsystems:

- Subsystem "formation of an innovative project".

- Subsystem "Information base of scientific and innovative activity".

- Subsystem "support for analysis and evaluation of innovative projects".

- Subsystem "support for stakeholder communications".

- Subsystem "working with intellectual property".

- Subsystem "support of experts and formation of Competence Centers".

- Subsystem "monitoring and management of innovative projects".

- Subsystem "Simulation of innovation activity".

- Subsystem "forming templates for innovative projects".

- Subsystem "automation and accounting of preliminary and scientific and technical expertise".

- Subsystem "maintaining the register of experts".

- Subsystem "system Administration and information Security" and others.

The DP provides four levels of access:

- The level of public access.

- The level of personal access.

- Certified access level.

- The level of restricted access.

Subsystems consist of blocks that combine groups of tasks. For example, the subsystem "Information base of scientific and innovative activity" includes:

- Database support block (patents, intellectual property, partners, investors, consumers of innovations, etc.).

- Block of linguistic and semantic search, etc.

The subsystem "support for analysis and evaluation of innovative projects" includes the following blocks:

- Block "Analysis of innovative projects".

- The block "Methodological support for innovation" (search for analogues, "packaging" of projects, registration of property rights, etc.).

- Block "Support for training in the design of innovative projects".

- Block "support for calculations in innovation" (investment performance indicators, quantitative, qualitative and cost assessment of the results obtained, etc.).

- Block "Support for scientific study of projects", etc.

The implementation of these tasks requires the use of a wide range of mathematical methods to solve the problems of innovation.

The DP uses mathematical methods to support decision-making in the innovation sphere. The issues of measuring and evaluating various aspects of innovative projects are considered. Without numerical values of qualitative characteristics, it is impossible to make estimates and make decisions.

The degree of innovation is the measure by which an investor decides to support a project. This measure is based on evaluation theory and measurement theory. Dimension theory is also used. In the future, it will be necessary to formulate new units of measurement related to the measurement of the degree of innovation, the degree of realizability, the degree of novelty, etc.

The methods of utility theory and value theory are used to justify project decisions. These sections are necessary for the formation of criteria for the success and feasibility of innovative projects.

Here we use mathematical methods and models that allow us to display subjective qualitative judgments of subjects on a numerical scale (of some type) in order to formalize value judgments about the project. Various types of evaluation and measurement scales are used, their applicability, ways of construction and use. One of the DP services supports evaluating the effectiveness of innovations.

To prepare a decision on project support, we use methods of generalizing information to build integrated concepts that give a General and final assessment of the project as a whole. To work with weakly structured information, the apparatus of semantics, knowledge, and ontologies in the field of innovation. Semantic methods of working with information are of paramount importance. This is due to the widespread use of the Internet, the use of cloud technologies, and great achievements in the field of web standards. Structured metainformation based on the RDF standard (and a number of others) allows you to present information in the form of knowledge. In other words, this is a step towards separating knowledge from specialists (experts) in order to be able to store and use knowledge, regardless of the presence of the source of knowledge itself. Based on this principle, virtual competence centers will be formed in the DP.

For the successful implementation of the semantic web concept, an ontological network of concepts of innovation is formed, taking into account the applied areas of activity.

The DP solves modeling problems, in particular, ontological and simulation. In fact, innovation is aimed at changing the world around us. But the consequences of these changes are not always obvious at the beginning of the project. To successfully promote the project and its implementation, it is necessary to model not only the innovative product itself, but also its impact on the design environment, production environment, distribution and use environment. Such modeling will allow, on the one hand, to prove the usefulness and profitability of an innovative product (in the case of positive modeling results). On the other hand, stop the project in time and avoid unnecessary costs (in case of negative modeling results).

It is advisable to implement the DP in three queues. 


\section{Conclusion}

The tasks of the first stage are the"first aid" for the author (and expert) in terms of information and methodology: dictionaries, reference books, regulatory framework, standard competition documents, methodological assistance, etc. This allows you to speak the same language with each other, understand each other's problems, find compromise solutions, and so on.

The tasks of the second stage of the DP include the tasks of extracting information, creating information, converting it, storing it, presenting it to stakeholders, processing (detailing, integration), developing templates, typing, and evaluating it. As well as mechanisms for working with information that allows you to prepare a project to get a positive decision from the investor to support the project.

Tasks of the third stage are intended for the intellectualization of works implemented in the first and second stages. In fact, it should be an intelligent information and advice system using artificial intelligence methods.

\section{References}

1. URL: ru.wikipedia.org/wiki/Undetectable concept (accessed date: 10.10.13).

2. Schumpeter, J. A. Theory of economic development. Moscow: Progress, 1992. 231 p.

3. Foster R. Production update: attackers win. Moscow: Progress, 1987. 147 p.

4. Twiss B. Management of scientific and technical innovations. M.: Ekonomika, 1989. p. 37.

5. Santo B. Innovation as a means of economic development. M.: Progress, 1990. 291 p.

6. Drucker P. How to ensure success in business. K.: Ukraina, 1994. p. 41.

7. Porter M. Competition: textbook. manual; [trans. Moscow: Williams, 2001. 495 p.

8. Hamel G., Prahalad K. Competing for the future. Moscow: Olimp-Business, 2002. 216 p.

9. Nelson R., Winter S. Evolutionary theory of economic changes. Moscow: Finstatinform, 2000. p. 46.

10. Yakovets Yu. Acceleration of scientific and technological progress: theory and economic mechanism. Moscow: Ekonomika, 1988. p. 95.

11. Morozov Yu. Innovation management. M.: UNITYDANA, 2000. p. 6.

12. Fatkhutdinov R. Competitiveness: economy, strategy management. M.: INFRA-M, 2000. P. 279.

13. Medinsky V. Innovation management. M.: Infra M, 2002. P. 5.

14. Hipel V. U. S. high technology trade and competitiveness. Staf-freport. U.S. Department of Commerce, 1985, p. 19.

15. Rts H. Managing high technology companies Blmont. N.Y., 1983, p. 7.
16. Frimen $\mathrm{K}$. The Economics of industrial innovation; 2nd edn. Frances Pinter, London, 1982, p. 38.

17. Rotvell R., Gardiner P. Invention, innovation, reinnovation and the role of the user / / Techonovation, 1985, No. 3, p. 168.

18. Tidd D., Bessant D., Pavitt K. Managing innovation. John wiley \& Sons, LTD, Chichester, 2001, p. 38.

19. The law of Adornment "Pro shnovatsshnu diyalnist" / / Golos Adornment. 2002. 9 serp. p. 10.

20. URL: ru. w ikipedia.org/wiki/Innovation (date of request: 10.10 .13 ).

21. Okhunov D.M. Theoretical and methodological aspects of the development of marketing automated information systems. - Tashkent: FAN, 2010.208p.

22. Novikov A.M., Novikov D. A. Metodologiya. - M.: SYNTEG, 2007. - 668 p.

23. Kupriyanov K. V., Nesterov V. V. the Principle of changes in innovation activity. Science and innovation in the XXI century: current issues, discoveries and achievements: collection of articles of the XVII International scientific and practical conference. - Penza: "Science and Education". 2020. -220 p.

24. Semenov S. V. Innovations. Integration of scientific knowledge into production activities. Eurasian Scientific Association. 2018. no. 6-1 (40). Pp. 4345.

25. Kupriyanov K. V. Concept of automation tools for supporting innovation activities. Science and innovation in the XXI century: current issues, discoveries and achievements. Collection of articles of the XVII international scientific and practical conference. Penza: "Science and Education", 2020, $220 \mathrm{p}$. 